\title{
EDITORIAL: IN PRAISE OF WRITING
}

\author{
Christopher Fox
}

We live in an era when culture is, so we are told, dominated by the visual, from blockbuster movies to cat videos to emojis. There's some truth in this - images are everywhere - but this is also an intensely verbal age and, in particular, a time of writing, in which people are as likely to communicate in text as in speech.

For those of who write about music this is good news, at least in part. Never has it been easier to find out about musicians: a few search terms and a host of material is at one's fingertips. On the other hand, because these days we so rarely write on paper, a lot of this writing may not survive for future generations. I worry that our digital archives, whether of text, audio or visual images, are only a format update or an iCloudburst away from oblivion.

Music is essentially ephemeral so writing has been a vital means of preserving at least some sort of record of the sounds that people have made. Perhaps somewhere, for example, we will discover a treasure trove of music from previous centuries that, because it was not created by men, was not published, but was nevertheless written down, or at least written about. Writing can become the means by which forgotten music regains its voice.

It will be interesting to see if this is the case with the music of Michael Tippett, subject of a marvellous new biography by Oliver Soden. Tippett was a successful composer during his lifetime, his work commissioned and performed by many major orchestras, festival and opera companies, widely recorded and broadcast, published in a distinguished edition, but since his death in 1998 the number of performances of his work has dwindled.

Perhaps it's a matter of personality: Tippett was a beguiling presence and his effervescent charm provided a distraction from the sheer strangeness of his music. Now we are left with the music, its awkward beauty the result of a series of collisions between Tippett's modernist sensibilities and his rather more conservative musical vocabulary, and it doesn't seem to suit the reductionist tastes of the present. Tippett's music doesn't fit the dominant metanarratives of the music of the last hundred years and so it's dropped out of circulation. Neo-classical/pastoral/collage/symphonic? That's just not A Thing.

Soden's book, Michael Tippett: The Biography (London: Weidenfeld and Nicholson, 2019) will surely help to rehabilitate Tippett's music. It enables us to understand the nature of Tippett's achievements by establishing the changing contexts in which the composer worked. Soden's research involved is impressive in itself, replacing Tippett's own rather wayward recollections of his life with a wealth of documentary evidence, but the way he draws it all together is even more compelling.

The portrait that emerges is that of a man for whom the political fashions of contemporary liberal society - first socialism, then pacificism and, later, hippiedom - were always attractive, sometimes almost 
too attractive. The transition from Tippett's vehement 30s Trotskyism to his benign 'play it cool, baby' stance in the late 60 s may seem modish to a fault. At the same time, however, his musical habits of mind were enduring: a devotion to long-limbed contrapuntal lines underpinned by chromatically inflected modal harmony and agile rhythms. Soden also observes that Tippett was a composer who didn't write many repertoire works, the classical music equivalent of the small-talk that keeps conversation going. Instead his output is dominated by large-scale works that require a lot of resources.

What has any of this got to do with TEMPO, a journal devoted to the music being made now? By definition the composers whose music features here tend to be flourishing, in the midst of lively, successful careers, so I think it is instructive to consider what can happen when a composer is no longer with us to represent their work and when many of the people who might have been advocates for their artistic legacy have other things on their mind. The disappearance of Tippett's work from concert programming is a case study in how even well-documented music can fall into silence.

Yet it's possible to imagine, as Oliver Soden's generously perceptive writing brings Tippett and his music vividly back to life, that other people - people who play, conduct, promote - will also want to hear it again. On the one hand it is, of course, music of its time, from the Jungian psychodrama of $A$ Child of Our Time to the synoptic panorama of The Mask of Time, but it is also music conceived at a tangent to the contemporary world, refracting changing aesthetic preoccupations through Tippett's entirely individual musical language.

Above all, Tippett's music is generous, reaching out to embrace as much of the world as it possibly can and possibly, sometimes, for some tastes, rather more than it can. This issue of TEMPO is possibly the most ethnically diverse of any since I became editor, with writing that covers music from across Europe to Japan and Australia, embracing issues of nationality, cultural representation, human rights, the displacement of peoples, and the agency of voiceless minorities. I think Tippett would have approved. 